\title{
UTILIZAÇÃO DE ABRIGOS TERMO-HIGROMÉTRICOS ALTERNATIVOS
}

\author{
Marcos de Oliveira Valin Jr \\ Mestrando em Física Ambiental - UFMT / Professor do IFMT \\ marcos.valin@cba.ifmt.edu.br \\ Flávia Maria de Moura Santos \\ Professora do Programa de Pós-Graduação em Física Ambiental - UFMT \\ flavia mms@hotmail.com
}

Marta Cristina de Jesus Albuquerque Nogueira

Professora do Programa de Pós-Graduação em Física Ambiental - UFMT mcjanp@gmail.com

Carlo Ralph De Musis

Professor do Programa de Pós-Graduação em Física Ambiental - UFMT / Universidade de Cuiabá - UNIC carlo.demusis@gmail.com

José de Souza Nogueira

Coordenador do Programa de Pós-Graduação em Física Ambiental - UFMT nogueira@ufmt.br

\begin{abstract}
RESUMO
Este trabalho teve por objetivo levantar os tipos de abrigos alternativos para termohigrômetros (temperatura e umidade) utilizados, reproduzi-los e testa-los para comparação dos dados obtidos a partir de um padrão de referência, instalados em campo aberto para garantir o mesmo ambiente para o estudo, visando avaliar e qualificar esses abrigos quanto ao seu desempenho, custo e praticidade de manuseio para utilização em pesquisas de clima urbano. Com os dados coletados realizaram-se diversas analises gráficas e estáticas. Com base no desempenho dos abrigos alternativos analisados, tem-se que os abrigos fabricados com tubo de PVC na vertical e com pote de sorvete não se demonstram eficientes para a coleta de dados em pontos fixos, principalmente se utilizados durante o dia. Quanto aos demais tipos, o com pratos plásticos, tubo de PVC na horizontal e casa de madeira, se mostraram alternativas viáveis quanto ao desempenho, cabendo analisar o local onde será utilizado para definir qual deles melhor se adapta, pois o horizontal depende de já conhecer o sentido da direção do vento, o de madeira do espaço disponível devido ao seu tamanho e peso e o de pratos depende da disponibilidade de pratos plásticos na cor branca.
\end{abstract}

Palavras-chave: Abrigos alternativos; Abrigos para termo-higrométricos; Clima urbano.

\section{SHELTERS TERM-HYGROMETRIC USE ALTERNATIVE}

\begin{abstract}
This study aimed at reviewing the types of alternative shelter for thermo-hygrometers (temperature and humidity) used, play them and test them to compare data obtained from a reference standard, installed in the open to ensure the same environment for study, to evaluate and qualify these shelters for performance, cost and handling of practicality for use in urban climate research. With the collected data held various graphical and static analysis. Based on the performance of alternative shelters analyzed, it has the shelters made of PVC pipe vertically and ice cream pot does not
\end{abstract}

Recebido em 15/07/2015

Aprovado para publicação em 26/11/2015 
demonstrate efficient to collect data at fixed points, especially if used during the day. As for the other types, with plastic plates, pvc pipe horizontally and marries wood, proved viable alternatives for performance, fitting analyze where will be used to define which one best fits because the horizontal depends on already know the wind direction sense, the wood of the available space due to its size and weight and the dishes depends on the availability of plastic plates in white.

Keywords: Alternative shelters; Shelters for thermo-hygrometric; Urban climate.

\section{INTRODUÇÃO}

Nos estudos da climatologia urbana, que são importantes para a garantia da qualidade de vida, é quase que indispensável a realização de trabalhos em campo, visando à obtenção de dados para serem analisados, envolvendo muito mais do que somente observação e análise, normalmente visam à obtenção de dados.

Dentre os elementos do clima, pode-se afirmar que os que mais afetam o conforto humano são a temperatura e a umidade do ar, sendo a radiação solar e ventilação, os fatores climáticos mais representativos no processo (GIVONI, 1976). Esses dados só podem ser obtidos através do uso de equipamentos e sensores específicos, sendo que muitos desses necessitam de abrigos meteorológicos para proteção dos sensores e também para garantir a qualidade e padronização dos dados.

Um dos desafios atuais na área de pesquisa de clima urbano refere-se à padronização dos procedimentos de coleta e análise de dados (OKE, 2005). A padronização dos instrumentos de coleta e abrigos utilizados é fundamental para a qualidade desses estudos microclimáticos, visto que esses dados geralmente são a base desses estudos, bem como garantir que sejam de fácil acesso e baixo custo. Outro ponto relevante nos estudos microclimáticos nas cidades é a questão da segurança.

Referente as coletas de dados meteorológicos nas cidades, Azevedo (2001) apud Castelhano e Roseghini (2011) relata sobre a problemática envolvida, uma vez que, em função das rugosidades geradas pela cobertura e uso do solo, que se somam as edificações e ações antrópicas, é gerado um complexo climatológico único, que aumenta a responsabilidade da escolha dos pontos de coleta.

Pesquisas microclimáticas são realizados constantemente com o objetivo de subsidiar estudos de ilhas de calor, projetos de edificações, conforto ambiental e o planejamento urbano, utilizando estações fixas padrões, pontos de coleta fixo em vários pontos da cidade, o método do transecto móvel, entre outros para verificar diferenças entre os parâmetros climáticos em pontos de diferentes ocupações do solo. Estes estudos compreendem medidas de temperatura do ar e umidade relativa do ar relacionados com o perfil de uso e ocupação do solo, vegetação e altitude.

Em Cuiabá - MT, e não diferentemente nos outros estados do Brasil, pesquisas de sistemas urbanos são desenvolvidas majoritariamente por universidades e centros de ensino, onde os recursos são limitados e dependentes de editais ou mesmo de recursos próprios de pesquisadores. Para contornar essas dificuldades muitos sensores, abrigos e sistemas alternativos aos padrões são desenvolvidos, baseados na experiência e criatividade dos pesquisadores.

Os abrigos utilizados têm a função de permitir uma boa ventilação natural por todos os lados, bloquear a entrada de chuva e de radiação solar direta, permitir a entrada de radiação solar difusa. Pensado nisso, diferentes autores desenvolveram abrigos alternativos para realização de pesquisas, porém observa-se diferenças em seus formatos e posições de instalação.

Conhecer os tipos de abrigos possíveis e avaliá-los quanto a sua utilização em situações diversas é de grande importância para validação e precisão de estudos microclimáticos. Além disso, esses abrigos devem ser leves e duráveis para serem viáveis de se utilizar.

Conforme Costa et al. (2007), a padronização envolve nomenclaturas, métodos de trabalho e análise, de forma que a transmissão da tecnologia desenvolvida possa ser melhor compreendida e aplicada para as diversas realidades. Essa é uma preocupação também

$\begin{array}{llllll}\text { Caminhos de Geografia } & \text { Uberlândia } & \text { v. 17, n. } 57 & \text { Mar/2016 } & \text { p. 74-91 } & \text { Página } 75\end{array}$


brasileira que detém diversos grupos de estudo na área de clima urbano se consolidando, só que trabalhando muitas vezes de forma isolada.

Como forma de fornecer subsídio aos estudos de clima urbano o objetivo geral deste trabalho é verificar as influências de diferentes tipos de abrigos para termo-higrômetros em pontos fixos.

Os objetivos específicos consistem em identificar na literatura os tipos de abrigos para termohigrômetros já estudados / utilizados; construir os principais tipos de abrigos identificados; realizar coleta de dados com os diferentes tipos de abrigos; e analisar os dados obtidos.

\section{ABRIGOS ALTERNATIVOS UTILIZADOS EM PESQUISAS}

\section{ABRIGO HORIZONTAL}

Barros (2012) utilizou um tubo de PVC (Policloreto de vinila) branco no sentido horizontal para passagem de ar com $50 \mathrm{~mm}$ de diâmetro por $50 \mathrm{~cm}$ de comprimento fixado ao interior de um segundo tubo, com dimensões de $100 \mathrm{~mm}$ de diâmetro por $60 \mathrm{~cm}$ de comprimento, para medições móveis, conforme a Figura 1.

Figura 1. Abrigo horizontal para medições móveis.
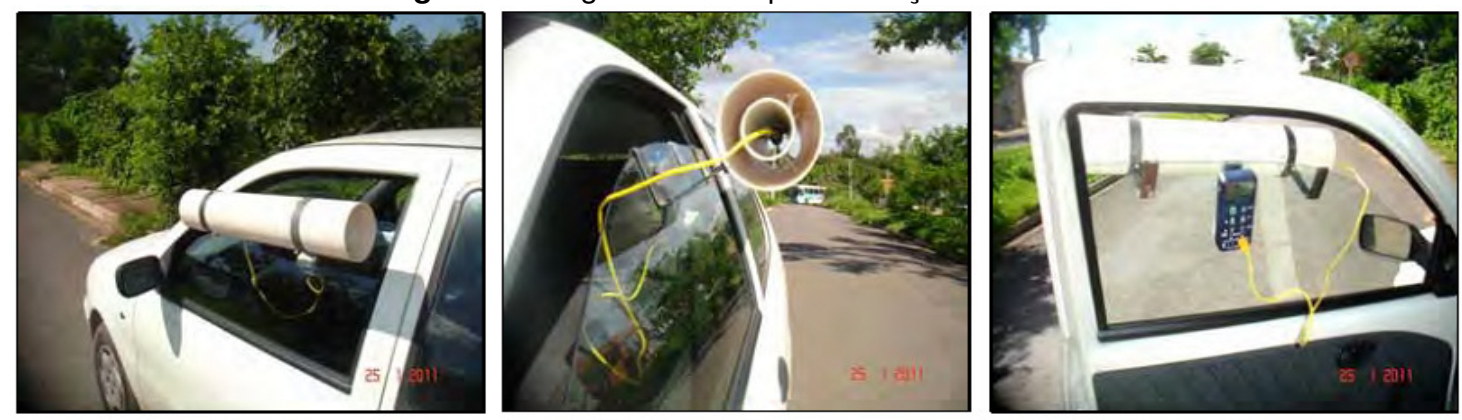

Fonte: BARROS (2012).

Oliveira (2007) utilizou metodologia similar, porém em medições fixas, sendo um conjunto constítuiído por 4 tubos de PVC também de cor branca, de $30 \mathrm{~cm}$ de comprimento e $100 \mathrm{~mm}$ de diâmetro, todos dispostos horizontamelte em suporte metálico à altura de $2 \mathrm{~m}$ do solo, com os respectivos sensores em seu interior, pendurados paralelos uns aos outros com uma distância de $45 \mathrm{~cm}$ entre eles, sendo o suporte posicionado na direção perpendicular a direção do percurso do sol. Entre os 4 tubos utilizados, variou-se que no primeiro a ventilação é natural e sem isolamento, no segundo com ventilação forçada, o terceiro com ventilação forçada e isolamento e no último com ventilação natural e isolamento térmico, conforme Figura 2.

Figura 2. Abrigo horizontal para medições fixas.

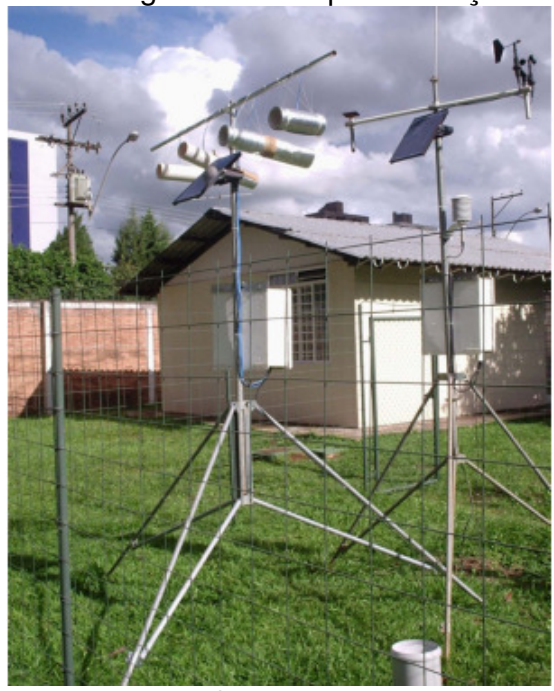

Fonte: OLIVEIRA (2007). 


\section{ABRIGO VERTICAL}

Cox (2008), Franco (2010), Santos (2012) e Franco (2013) utilizaram um tubo de PVC branco no sentido vertical perfurado e para permitir a passagem de ar na parte superior do tubo foi colocado um funil branco para proteger o sensor da radiação solar direta e precipitações para medições moveis (Figura 3).

Figura 3. Abrigo vertical para medições.

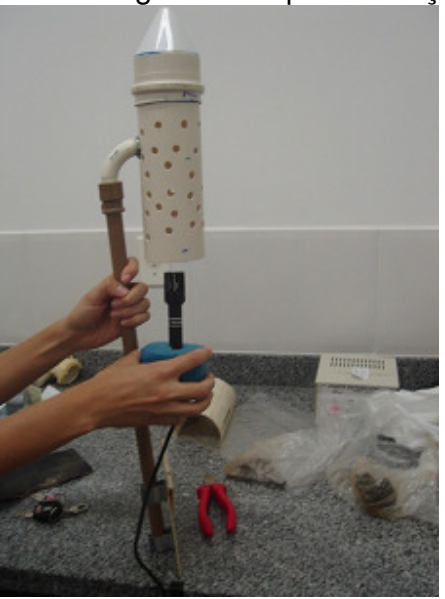

Fonte: FRANCO (2010).

\section{ABRIGO DE PRATOS}

Armani e Galvani (2006) inspirados no modelo 4100310 - Plate Gill Radiation Shield (Campbell Inc.) construíram um abrigo com chapa de ferro galvanizado de $0,5 \mathrm{~mm}$ de espessura e pintado com tinta esmalte na cor branca brilhante, diâmetro de $220 \mathrm{~mm}$ e pé direito central de $240 \mathrm{~mm}$ (Figura 4).

Figura 4. Abrigo de chapas de ferro.

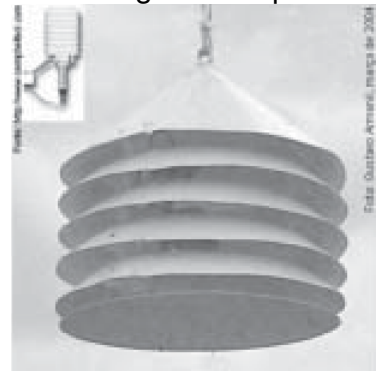

Fonte: ARMANI e GALVANI (2006).

Costa et al (2007), também inspirado no modelo da Campbell, realizaram ajustes no modelo, substituindo as chapas metálicas por pratos plásticos em seu abrigo para medições fixas (Figura 5).

Figura 5. Abrigo de pratos plásticos.

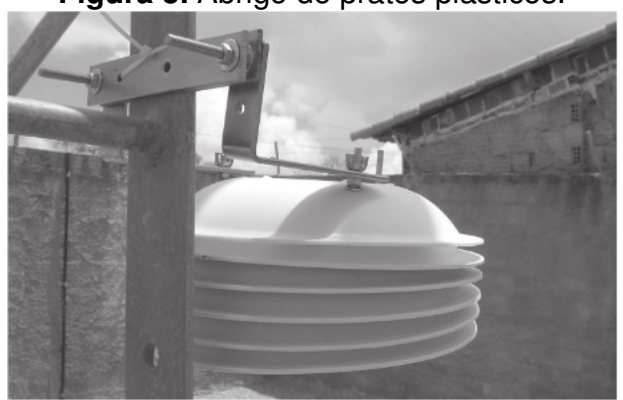

Fonte: COSTA, et al. (2007) 


\section{ABRIGO DE POTE DE SORVETE}

Ribeiro (2015) instalou os dataloggers sob as copas das árvores das espécies (oiti e mangueira) em pesquisa sobre a avaliação do sombreamento, sendo que os abrigos utilizados foram de portes de sorvete com furos para garantir a circulação de ar, com o intuito de proteger os equipamentos da incidência de radiação e do intemperismo (Figura 6).

Figura 6. Abrigo de pote de sorvete

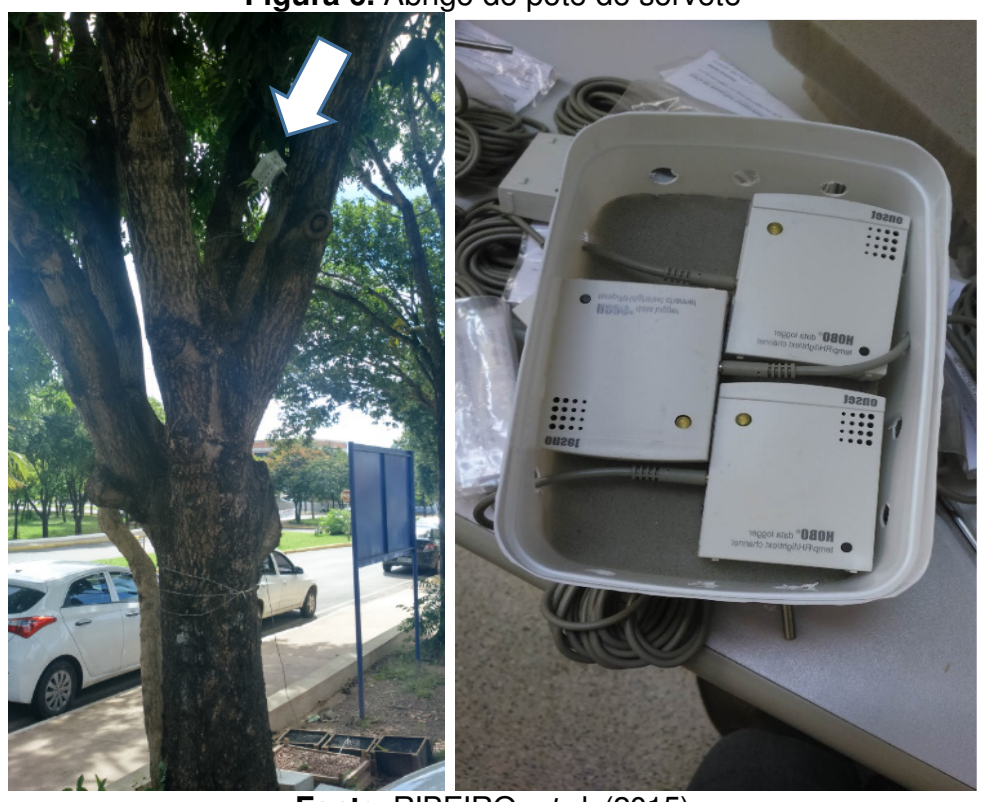

Fonte: RIBEIRO, et al. (2015)

\section{ABRIGO DE MADEIRA}

Nince (2013) utilizou registradores automáticos, marca HOBO, modelo U13, disposto no interior de abrigo meteorológico de madeira, com furos para ventilação a $1,5 \mathrm{~m}$ de altura em relação ao nível do solo (Figura 7). O mesmo tipo de abrigo de madeira foi utilizado por Oliveira (2007), mas, no entanto, foi instalado um psicrômetro onde foram coletadas foram coletadas informações sobre temperaturas de bulbo seco (TBS) e temperaturas de bulbo úmido (TBU).

Figura 7. Abrigo de madeira

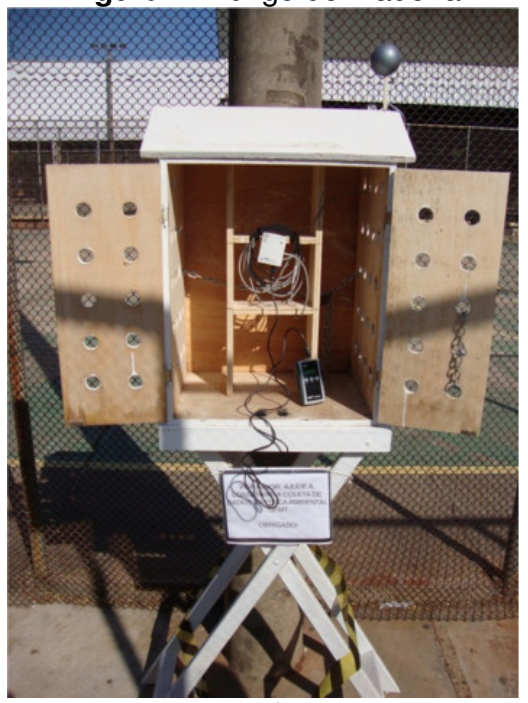

Fonte: NINCE (2013).

MATERIAIS E MÉTODOS

CONFECÇÃO DOS ABRIGOS

$\begin{array}{llllll}\text { Caminhos de Geografia } & \text { Uberlândia } & \text { v. 17, n. } 57 & \text { Mar/2016 } & \text { p. 74-91 } & \text { Página } 78\end{array}$


Os objetivos dos abrigos consistem na proteção contra a incidência de radiação e também proteção contra intempéries, sendo escolhidos com base no referencial de literatura os seguintes tipos:
a) Abrigo com tubo de PVC horizontal - "horizontal";
b) Abrigo com tubo de PVC vertical - "vertical";
c) Abrigo com prato plásticos brancos - "pratos";
d) Abrigo com pote de sorvete branco - "sorvete"; e
e) Abrigo de madeira - "madeira".

\section{ABRIGO COM TUBO DE PVC HORIZONTAL}

O abrigo foi produzido com tubos de PVC rígidos, na cor branca, sendo necessário $60 \mathrm{~cm}$ de comprimento no diâmetro de $100 \mathrm{~mm}$ e $50 \mathrm{~cm}$ de comprimento no diâmetro de $75 \mathrm{~mm}$ (Figura 8 , itens "a" e "b").

O tubo menor foi revestido na sua face externa por papel aluminizado (de uso convencional no preparo de alimentos) com o auxílio cola branca comum, para proteger de possíveis efeitos de radiação térmica (Figura 8, itens "c", "d" e "e").

Para centralizar o tubo menor no interior do tubo maior, utilizou-se de parafusos (Figura 8, item "f"), permitindo dessa maneira que 0 datalogger e sensor ficassem centralizados, com ventilação e protegido de intempéries.

As ferramentas utilizadas foram uma trena, uma chave de fenda e uma serra de arco, conhecida como "segueta".

Figura 8. Confecção do abrigo horizontal: (a) cortando os tubos. (b) tubos nas medidas. (c) material para preparação do tubo de $75 \mathrm{~mm}$. (d) preparação do tubo com cola. (e) colando o papel aluminizado. (f) fixação e posicionamento com o auxilio de parafusos.
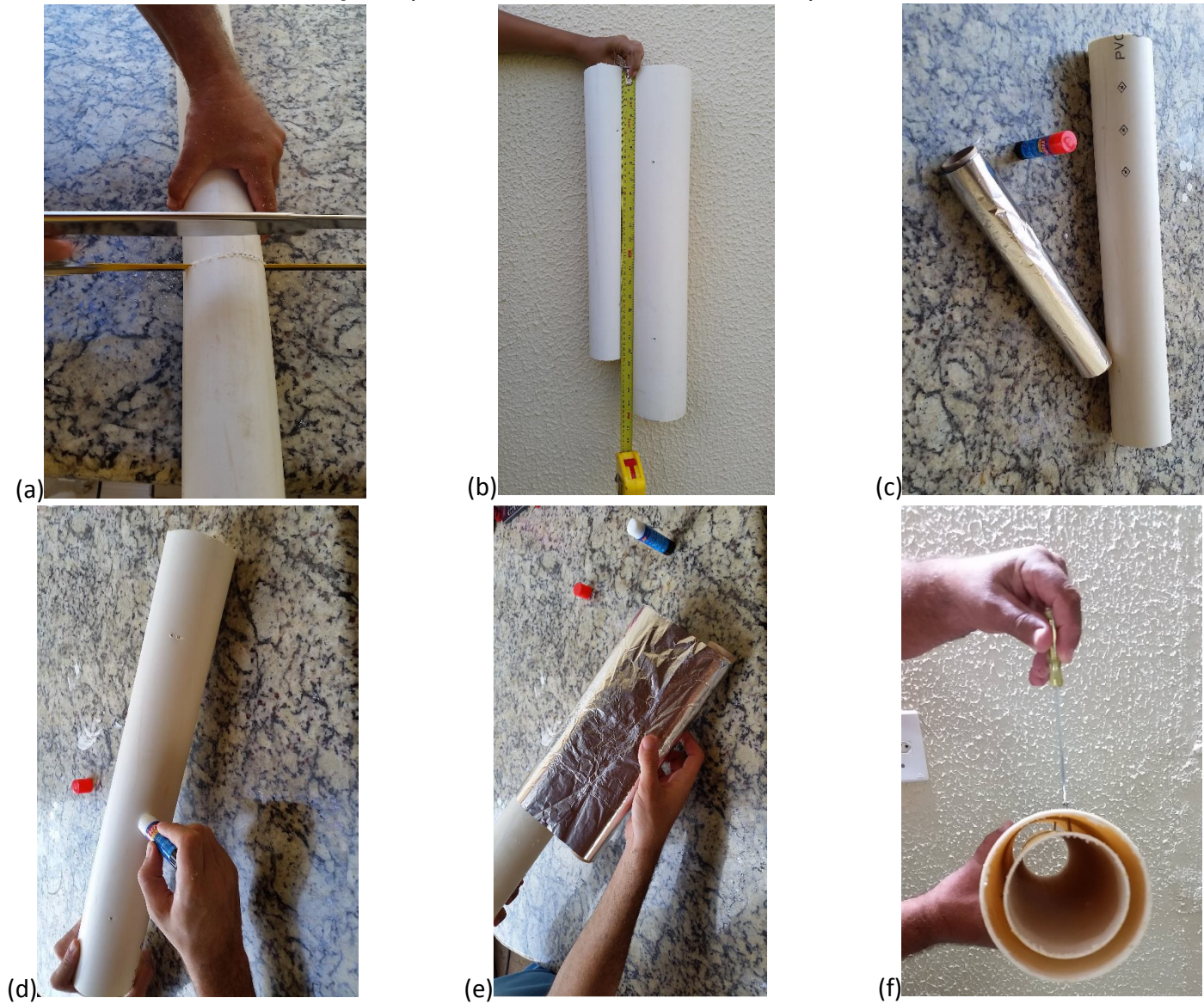
Para a instalação desse abrigo em locais fixos é fundamental conhecer o sentido da direção do vento predominante.

\section{ABRIGO COM TUBO DE PVC VERTICAL}

Para sua produção utilizou-se um tubo de PVC rígido, cor branca, de $75 \mathrm{~mm}$ de diâmetro e 25 cm de comprimento (Figura 9 - item "a").

O tubo foi perfurado, com o auxílio de uma furadeira com broca de $4 \mathrm{~mm}$, para permitir a passagem de ar (Figura 9 - item "b").

$\mathrm{Na}$ parte superior do tubo foi colocado um CAP (tampa para tubo de esgoto) para proteger o sensor da radiação solar direta e precipitações. Um suporte também foi confeccionado com peças de PVC.

Na parte inferior foi colocado uma esponja para servir de suporte ao sensor (Figura 9 - itens "c" e "d"). As ferramentas utilizadas foram uma trena, um estilete, uma serra de arco e uma furadeira com broca de $4 \mathrm{~mm}$.

Figura 9. Confecção do abrigo vertical (a) marcando os pontos. (b) furando. (c) peça semi-pronta.

(d) inserindo fundo no tudo.

(a)
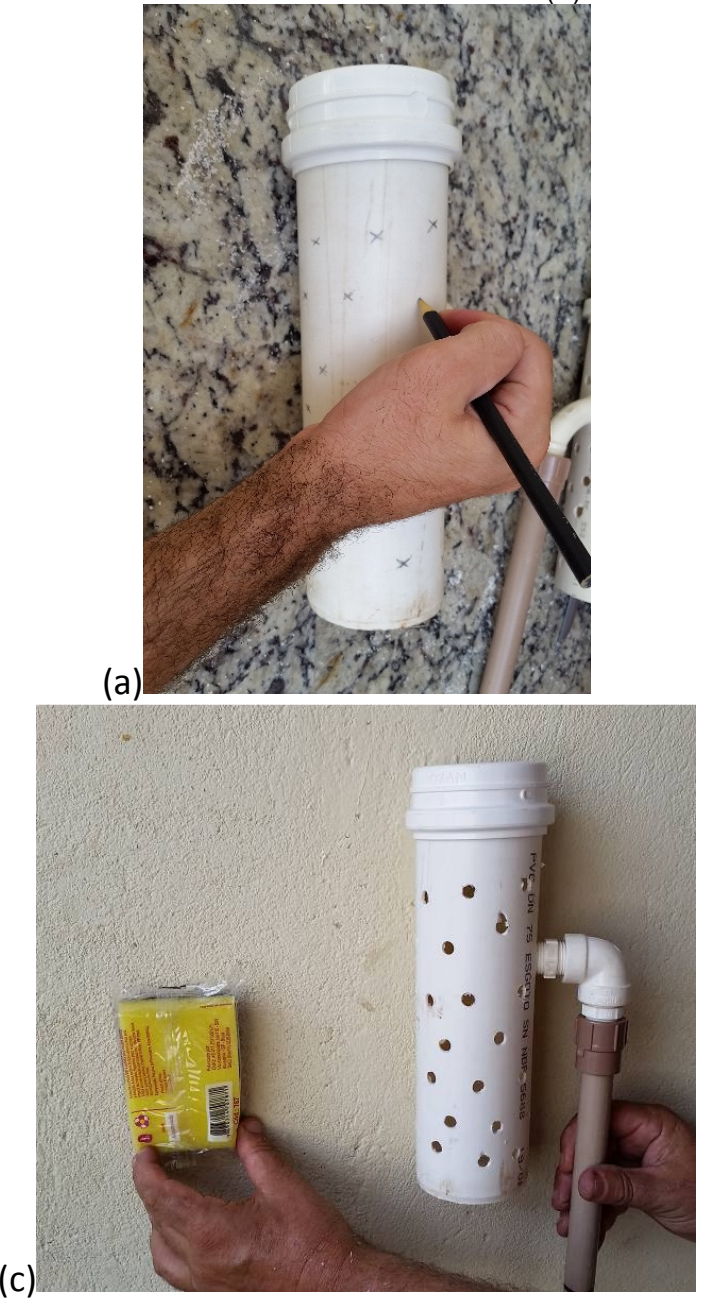

(b)

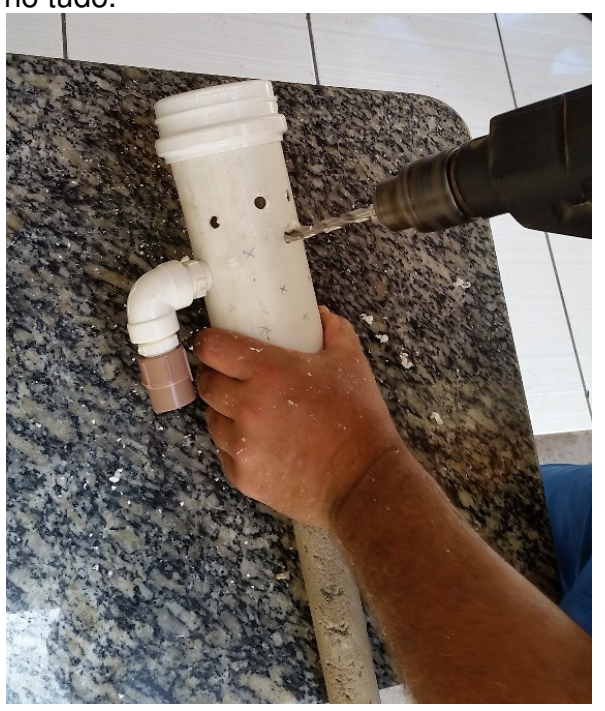

(d)

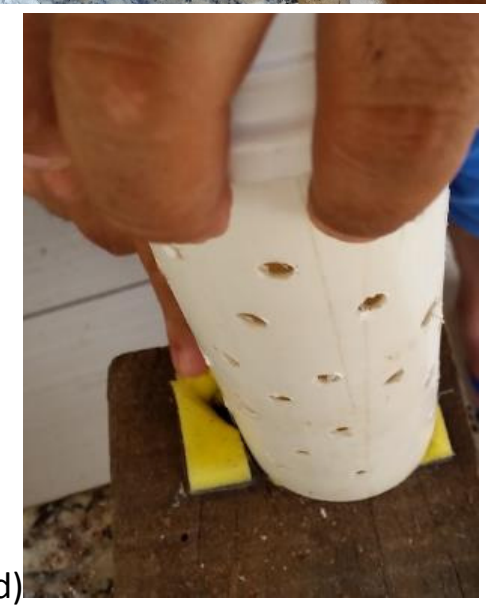

\section{ABRIGO COM PRATOS PLÁSTICOS}

Foi construído utilizando seis pratos redondos de plástico na cor branca (Figura 10 - item "a").

As dimensões dos pratos são as seguintes:

Fundo do prato (aba menor): $12 \mathrm{~cm}$; 
Aba maior do prato: $21,5 \mathrm{~cm}$;

Profundidade do prato $=3 \mathrm{~cm}$

Nos pratos intermediários foram realizadas aberturas, para o posterior posicionamento do sensor.

A distância entre os pratos foi de $2,5 \mathrm{~cm}$, assegurados através de mangueira de nível transparente contados, sustentados por duas barras galvanizadas roscadas de tamanho e 0,4 cm diâmetro, de modo a fixar os pratos sobrepostos (Figura 10 - itens "b", "c" e "d").

Os pratos superiores e os intermediários foram travados com o auxílio de porcas e arruelas junto com os espaçadores, sendo apenas o último prato inferior fixado com porcas do tipo borboleta, para facilitar o manuseio.

As ferramentas utilizadas foram uma trena, um estilete, uma serra de arco e uma furadeira.

Figura 10. Confecção do abrigo de pratos (a) cortando o centro dos pratos. (b) espaçadores. (c) etapa de
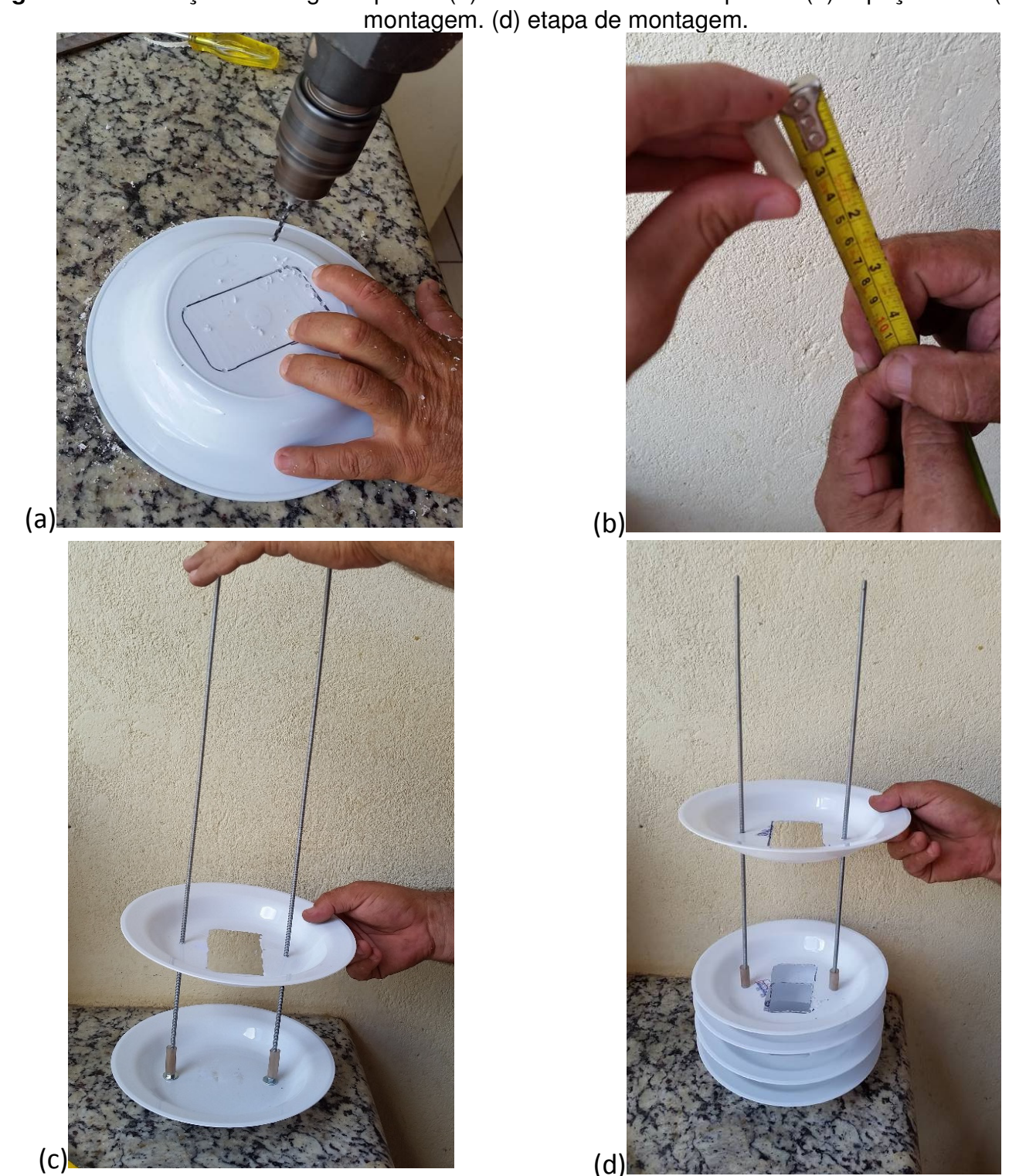

(b)

$$
\text { (c) }
$$

(d)

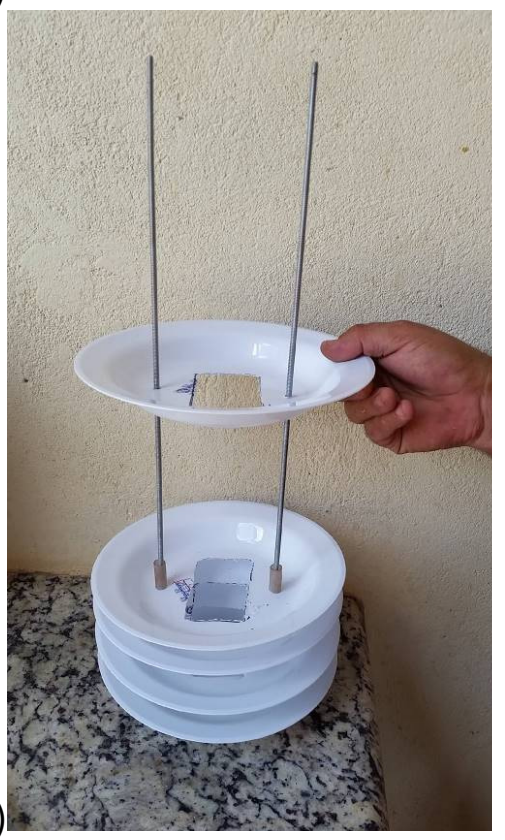

\section{ABRIGO COM POTE DE SORVETE}

O abrigo foi construído utilizando um pote de sorvete branco, inclusive a tampa na cor branca, com furos realizados com o auxílio de uma furadeira com broca de $4 \mathrm{~mm}$, para permitir a passagem de ar (Figura 11). A ferramenta utilizada foi uma furadeira com broca de $4 \mathrm{~mm}$.

\begin{tabular}{llllll}
\hline Caminhos de Geografia & Uberlândia & v. 17, n. 57 & Mar/2016 & p. 74-91 & Página 81
\end{tabular}




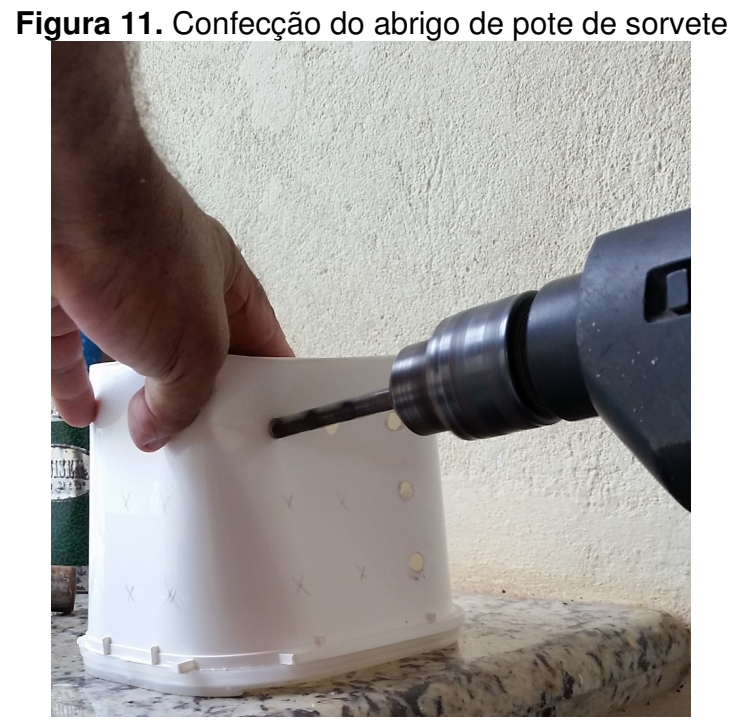

\section{ABRIGO DE MADEIRA COM FUROS}

Abrigo de madeira, sendo uma caixa nas dimensões de $54 \mathrm{~cm}$ de comprimento, $35 \mathrm{~cm}$ de largura e $65 \mathrm{~cm}$ de altura, com furos 20 furos de $2 \mathrm{~cm}$ de diâmetro em cada uma das 2 portas e outros 20 furos de $3,5 \mathrm{~cm}$ nas laterais (Figura 12).

Após a montagem do abrigo foi confeccionado um suporte para deixa-lo na altura de 1,5m.

O abrigo foi pintado, com tinta esmalte branca.

As ferramentas utilizadas foram uma trena, uma serra de arco, uma furadeira, uma serra copo de $32 \mathrm{~mm}$ e outra de $19 \mathrm{~mm}$, uma chave de fenda e um rolo de pintura.

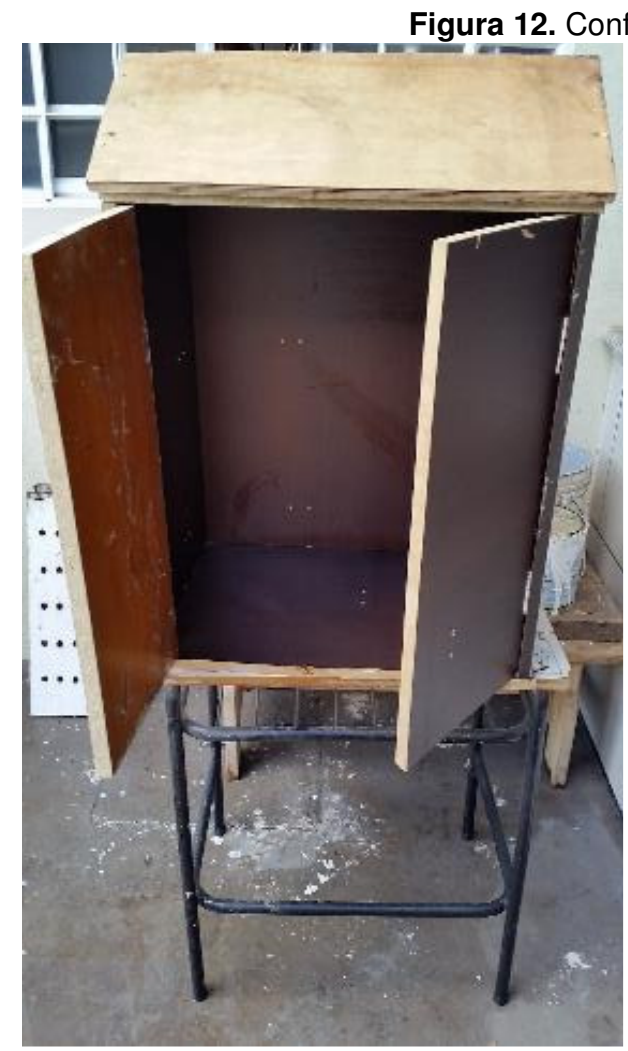

(a)

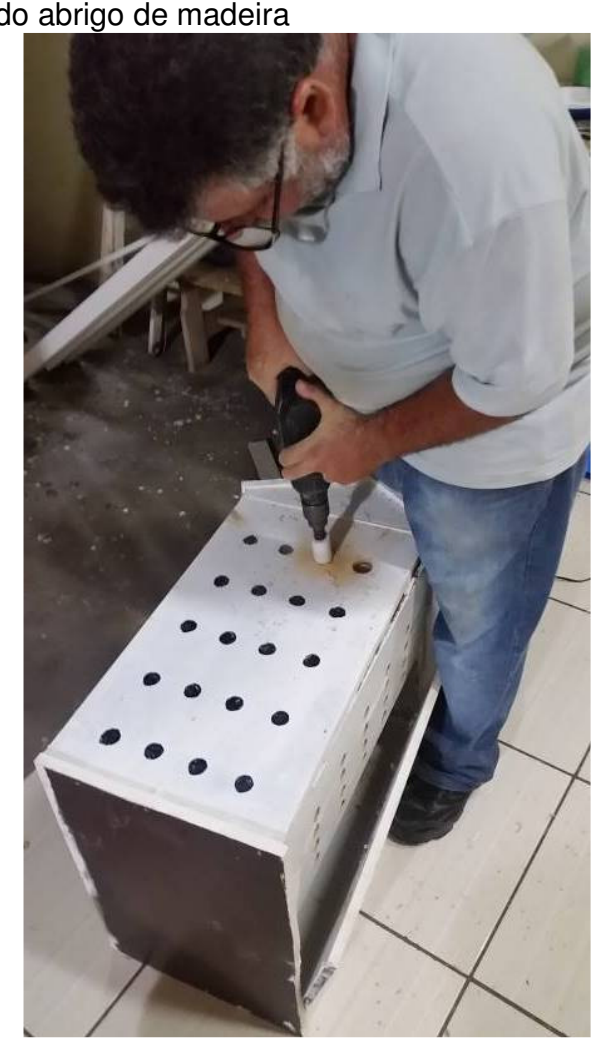

(b) 


\section{ESTAÇÃO DE REFERÊNCIA}

Como referência de comparação dos dados, optou-se por uma estação automatizada, sendo o modelo Vantage Pro $2^{\mathrm{TM}}$ da marca Davis (Figura 13), que é composta por conjunto de sensores que reúnem pluviômetro, sensores de temperatura / umidade, velocidade e direção do vento e pressão barométrica. O receptor do sinal wireless tem alcance de até $300 \mathrm{~m}$, e foi instalado a $5 \mathrm{~m}$, em abrigo de datalogger existente no local.

Figura 13. Estação automatizada - modelo Vantage Pro $2^{\mathrm{TM}}$

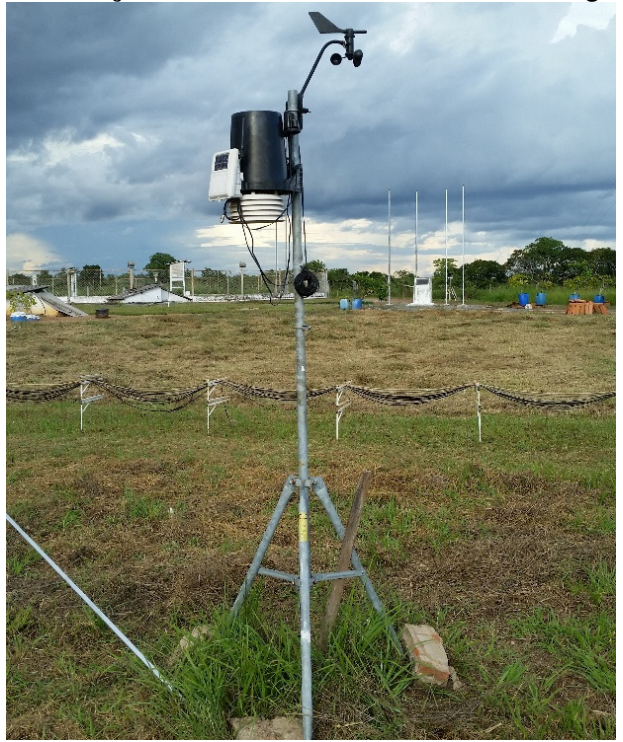

A umidade relativa e a temperatura do ar foram medidas por um termo-higrômetro (mod. 6382, Davis Instruments, USA) operando em intervalo de temperatura do $\operatorname{ar}-40^{\circ} \mathrm{C} \mathrm{a}+65^{\circ} \mathrm{C}$, e com acurácia de $\pm 0,4^{\circ} \mathrm{C}$ para um intervalo de $+15^{\circ} \mathrm{C}$ a $+40^{\circ} \mathrm{C}$. O sensor de umidade relativa do ar opera em um intervalo de $1 \%$ a $100 \%$ com acurácia de $\pm 3 \%$ (0\% a $90 \%$ UR), $\pm 4 \%(90 \%$ a $100 \%$ UR).

Anteriormente a instalação da estação, foi realizada limpeza e manutenção preventiva dos sensores e posterior calibração dos mesmos.

\section{SENSORES UTILIZADOS NOS ABRIGOS}

Os sensores utilizados neste estudo são do tipo Data Logger, modelo U12-012, de fabricação da Onset Compter Corporation (Figura 14), e é capaz de registrar medidas de temperatura, umidade relativa do ar, intensidade de luz. Com medidas de resolução de 12 bits, este registrador de dados reúne uma gama de dados gravados de 43.000 medições. (Onset Computer Corporation, 2015).

Figura 14. U12-012 Data Logger.

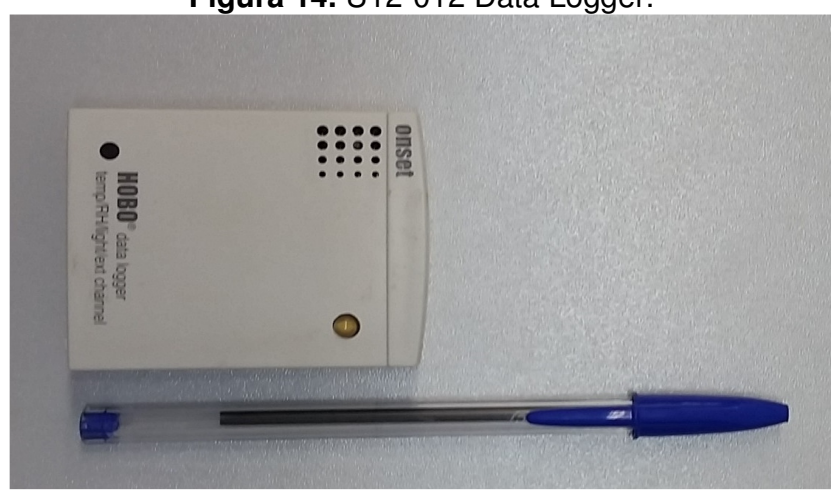


A Tabela 1 apresenta os dados de precisão do datalogger.

Tabela 1. Dados de precisão do sensor.

\begin{tabular}{c|c}
\hline Sensor: & Data Logger Hobo U12-012 \\
\hline Faixa de & $\begin{array}{c}\text { Temperatura do ar: }-20^{\circ} \text { a } 70{ }^{\circ} \mathrm{C} \\
\text { medição: }\end{array}$ \\
\hline Ucurácia: & $\begin{array}{c}\text { Temperatura do ar: } \pm 0,35^{\circ} \mathrm{C} \\
\text { Umidade relativa do ar: } \pm 2,5 \%\end{array}$ \\
\hline Resolução: & $\begin{array}{c}\text { Temperatura do ar: } 0,03{ }^{\circ} \mathrm{C} \\
\text { Umidade relativa do ar: } 0,03 \%\end{array}$ \\
\hline
\end{tabular}

Os sensores Hobo U12 - 12 utilizados foram verificados, sendo que foram ligados nas mesmas configurações e condições ambientais, em uma sala fechada e sem circulação de pessoas. A análise da comparação foi feita para os dados do sensor interno e também para o externo. 0 procedimento foi realizado durante o mês de março de 2015 e os dataloggers utilizados no procedimento de comparação foram os mesmos instalados posteriormente no campo.

Os resultados foram processados através de uma matriz de correlação, em que apresentaram valores sempre maiores do que 0,99 demonstrando a acurácia entre os sensores.

\section{INSTALAÇÃO DOS ABRIGOS}

O estudo foi desenvolvido nas dependências da Fazenda Experimental da Universidade Federal de Mato Grosso (UFMT), em espaço reservado para o desenvolvimento e monitoramento de pesquisas ambientais, localizada no município de Santo Antônio de Leverger (15 ${ }^{\circ} 46^{\prime}$ S e $56^{\circ} 05^{\prime}$ W), conforme localização na Figura 15.

Figura 15. Localização.

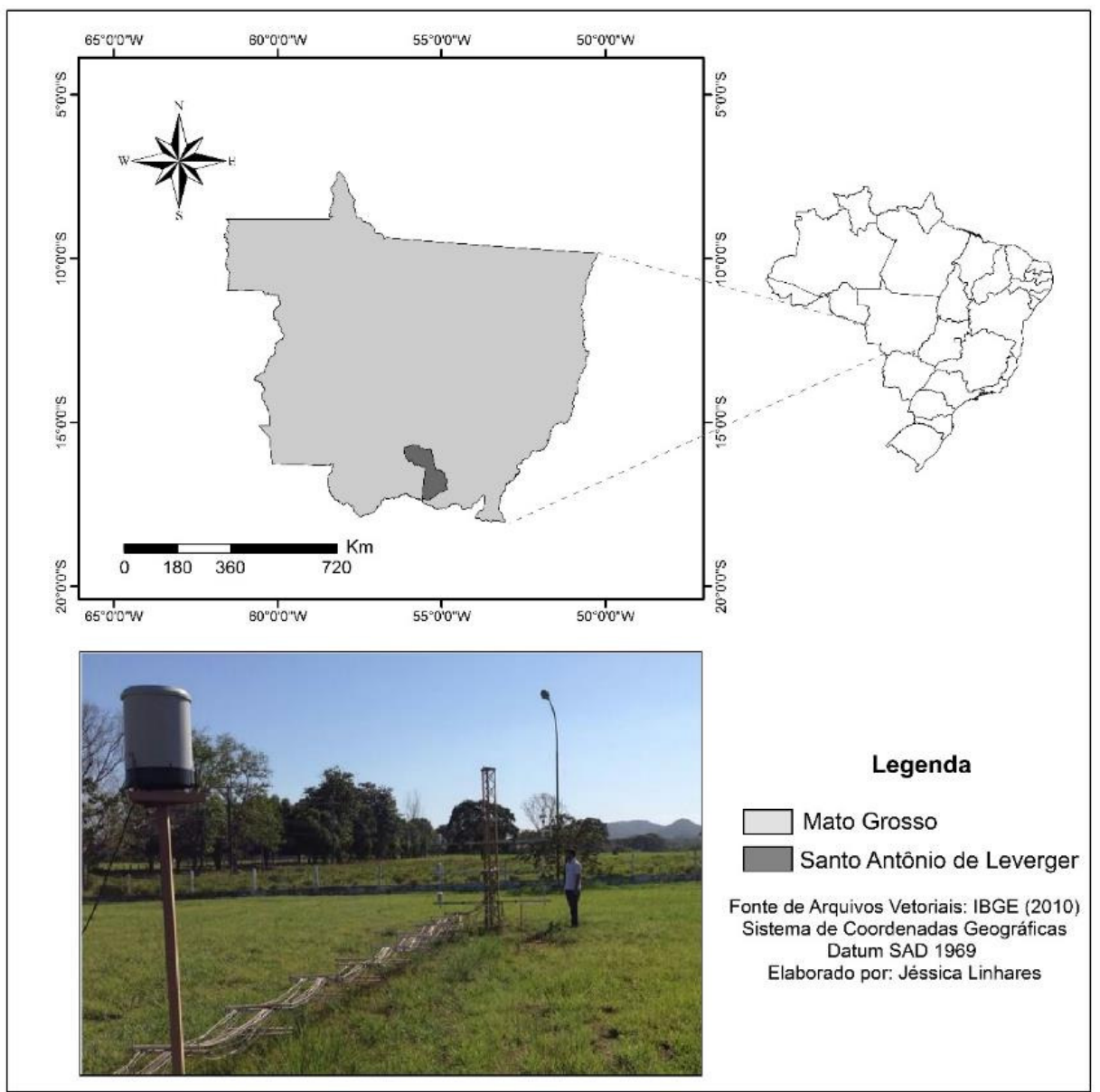


A região possui duas estações do ano bem definidas: uma seca (outono-inverno) e uma chuvosa (primavera-verão) (MAITELLI, 1994). O índice pluviométrico anual varia de 1250 a $1500 \mathrm{~mm}$ (CAMPELO JUNIOR, et al., 1991). Apresenta ainda baixa frequência e velocidade média do ar e seu clima está classificado como Aw, segundo a Classificação de Köppen.

Os abrigos construídos foram instalados de forma a manter a estrutura do solo e vegetação para que não haja alteração nas variáveis de medidas, sendo um campo aberto. Um cavalete foi construído para fixação dos abrigos (sorvete, horizontal, vertical e de pratos) com altura de aproximadamente $1,5 \mathrm{~m}$, conforme normas da OMM, sendo o abrigo de madeira e a estação de referências posicionadas próximas das extremidades do cavalete (Figura 16).

Figura 16. Equipamentos instalados.

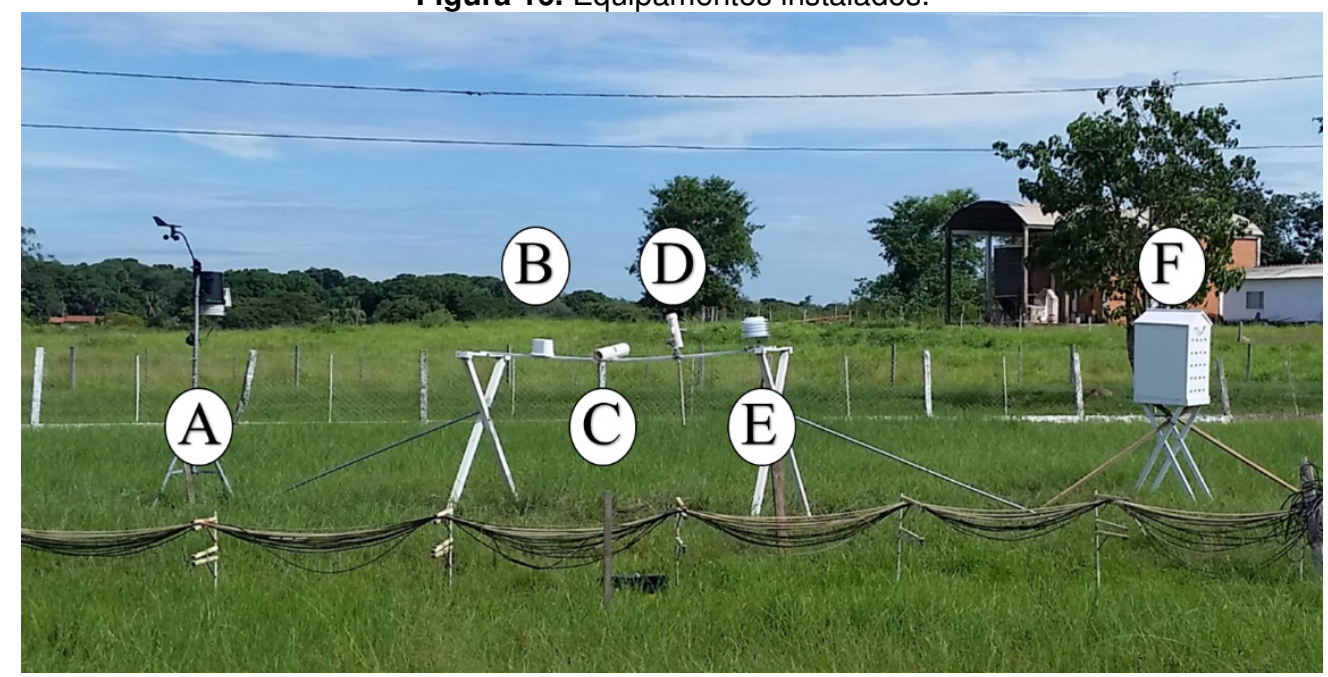

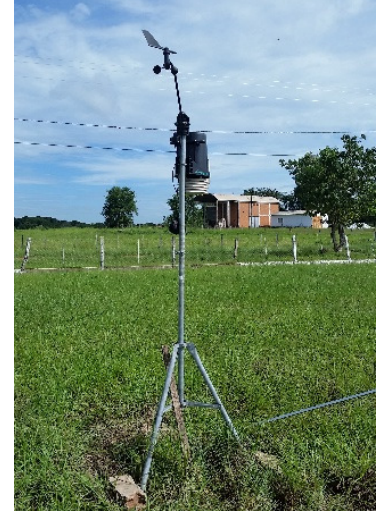

A

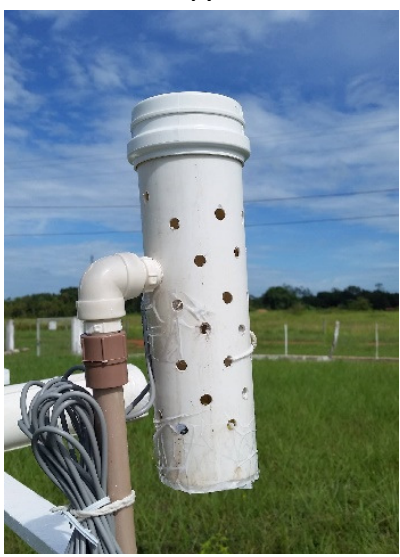

D

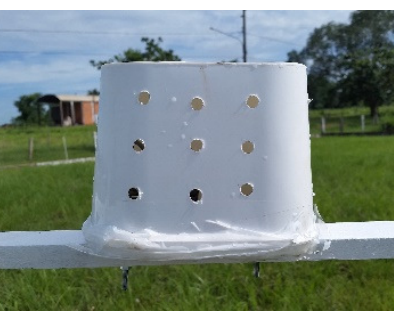

B

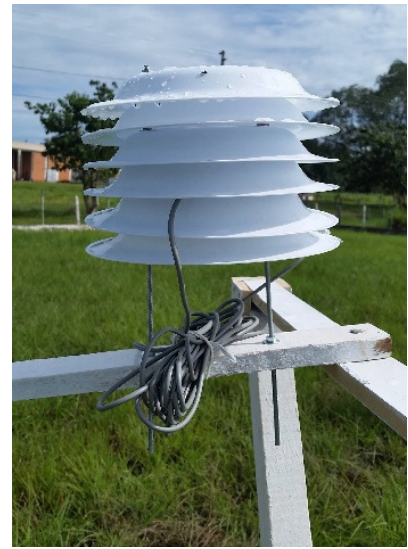

E

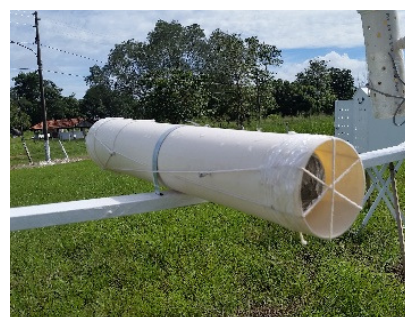

C

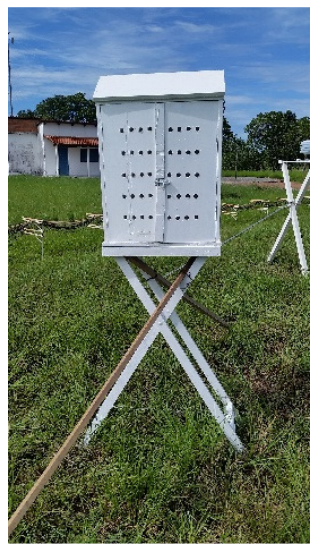

F 
A instalação ocorreu de maneira a ficar no sentido predominante da direção do vento, no caso Norte-Noroeste $\left(45^{\circ}\right)$.

Os abrigos foram instalados no mês de abril do ano de 2015, sendo na mesma data o início das medições.

Para a análise dos dados foram utilizados um período de 40 dias, entre os meses de abril e maio de 2015.

\section{ANÁLISE DOS DADOS}

Após a coleta dos dados, os mesmos foram organizados em planilhas no Microsoft Excel, bem como a geração de gráficos com as médias horárias e tabelas com as diferenças de temperatura registrada no padrão com os abrigos alternativos.

A análise estatística procedeu-se com a análise de variância multivariada (MANOVA) para verificação da significância dos dados, e também testes dos efeitos entre grupos em cada variável (ANOVA).

Para verificar se entre os abrigos as diferenças na temperatura e umidade relativa são significativas, realizaram-se os testes de comparações múltiplas Tukey HSD. Ambos os testes foram realizados utilizando-se o software SPSS Statistics versão 22.0.

Fatores como o tempo (horas) para fabricação de cada tipo de abrigo, bem como as ferramentas utilizadas, necessidade de serviços terceiros e tamanho para transporte também foram registrados durante a preparação dos abrigos.

\section{RESULTADOS E DISCUSSÕES}

\section{DESEMPENHO TERMO-HIGROMÉTRICO DOS ABRIGOS}

A observação das médias horárias da temperatura do ar do abrigo padrão com os abrigos alternativos estão ilustrados na Figura 17, e da umidade relativa do ar na Figura 18.

Entre as 18 e 06 horas, quando não há incidência de raios solares as temperaturas registradas nos abrigos alternativos foram menores do que o padrão, e quando há incidência dos raios solares a temperatura dos abrigos alternativos foram maiores do que o padrão.

Figura 17. Média horária das temperaturas do padrão e dos alternativos

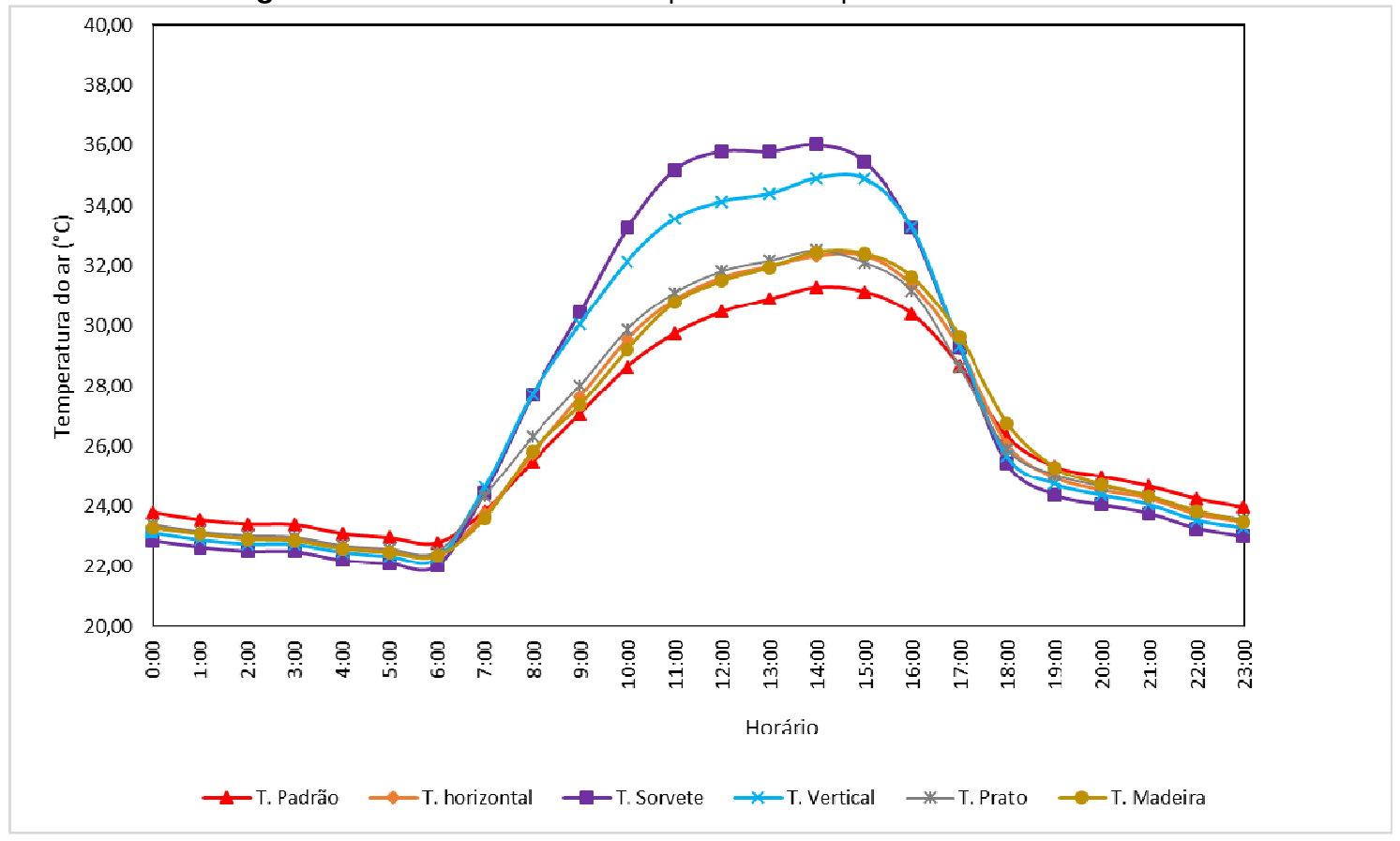


Figura 18. Média horária das umidades relativas do padrão e dos alternativos

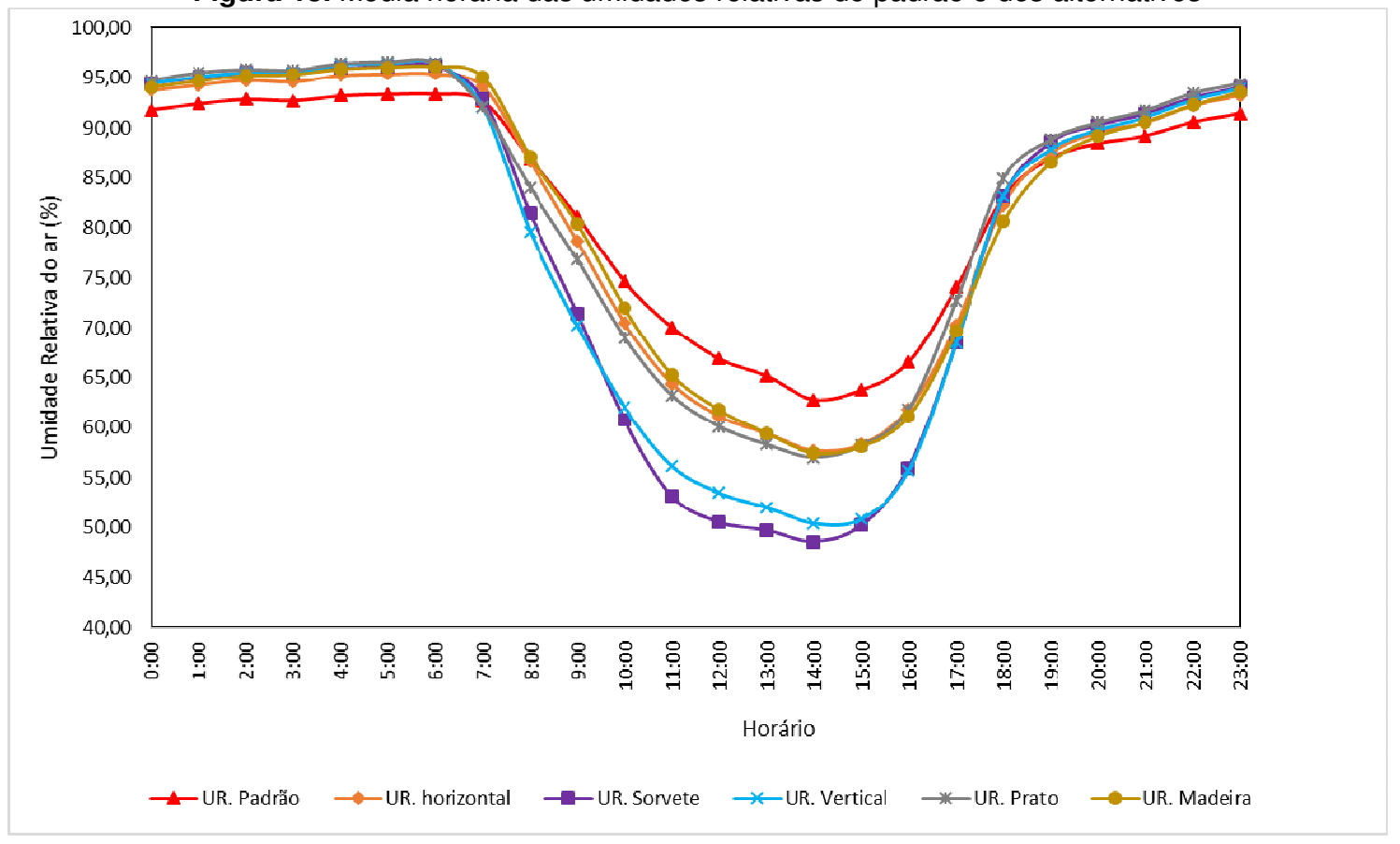

De maneira oposta ao que ocorreu com as temperaturas do ar registradas nos abrigos, com a umidade relativa do ar na média nos horários, observa-se que entre as 18hs e 07hs, quando não há incidência de raios solares as umidades relativas do ar registradas nos abrigos alternativos foram maiores do que o padrão, e quando há incidência dos raios solares a temperatura dos abrigos alternativos foi menor do que o padrão.

Nos abrigos do tipo sorvete e vertical observa-se que nos horários de maior insolação e aquecimento, entre 11 e 16 horas, ocorre um aumento da temperatura do ar dentro desses abrigos, ocasionado pela menor ventilação passiva, sendo que os furos existentes não foram suficientes, e ainda pela emissão de ondas longas pelos próprios abrigos. Entre esses dois abrigos, observa-se também que o do tipo sorvete tem temperaturas mais elevadas que o vertical, atribuindo-se essa diferença a fina espessura do material se comparado ao vertical que é de PVC.

Para testar a existência de diferenças significativas entre os abrigos quanto à temperatura do ar (T) e umidade relativa do ar (UR) foi utilizada a análise de variância multivariada (MANOVA). A temperatura e a umidade relativa foram consideradas como variáveis dependentes, e o fator "Tipos de abrigos" como variável independente. Os pressupostos de homocedasticidade e aderência dos resíduos a distribuição Normal foram avaliados pelos testes de Levene e Kolmogorov-Smirnov, respectivamente.

A MANOVA detectou diferenças significativas, conforme apresentado na Tabela 2, indicando que ao menos um tipo abrigo difere para um nível de significância menor que 0,1\% (altamente significativo) para as variáveis temperatura e na umidade relativa.

Tabela 2. Teste multivariado.

\begin{tabular}{lccc}
\hline Efeito do abrigo & Valor & Z & Significância \\
\hline Lambda de Wilks & 0,804 & 617,902 & $<0,001$ \\
\hline
\end{tabular}

A avaliação dos efeitos entre grupos em cada variável foi detalhada por Análises de variância Univariadas, detectando, em consonância, que o abrigo tem um efeito estatisticamente significativo tanto para temperatura $(F=957,238$; $p<0,001)$ como para umidade relativa $(F=$ 1143,931; $p<0,001)$.

A comparação post hoc entre as médias foi efetivada pelo procedimento de Tukey HSD, sendo os resultados apresentados nas Tabelas 3 e 4, e nas Figuras 18 e 19.

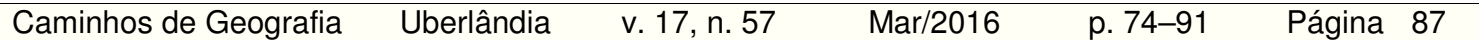


Tabela 3. Caraterização da temperatura $\left({ }^{\circ} \mathrm{C}\right)$ por abrigo e comparações múltiplas entre os abrigos

\begin{tabular}{|c|c|c|c|c|c|c|c|}
\hline \multirow{2}{*}{ ABRIGO } & \multirow{2}{*}{$M(D P)$} & \multicolumn{6}{|c|}{$\begin{array}{c}\text { COMPARAÇÕES MÚLTIPLAS } \\
\text { (diferenças entre as médias dos abrigos) }\end{array}$} \\
\hline & & Casa & Horizontal & Padrão & Prato & Sorvete & Vertical \\
\hline Casa & $26,43(4,12)$ & - & 0,044 & $0,173^{* *}$ & $-0,067^{*}$ & $-0,956^{* *}$ & $-0,790^{\star *}$ \\
\hline Horizontal & $26,39(4,08)$ & $-0,044$ & - & 0,129 ** & $-0,111^{* *}$ & $-1,000^{* *}$ & $-0,834^{\star *}$ \\
\hline Padrão & $26,26(3,43)$ & $-0,173^{\star *}$ & $-0,129^{* *}$ & - & $-0,240^{* *}$ & $-1,129^{\star *}$ & $-0,963^{* *}$ \\
\hline Prato & $26,50(4,10)$ & $0,067^{\star}$ & $0,111^{\star *}$ & $0,240^{* *}$ & - & $-0,889^{* *}$ & $-0,724^{* *}$ \\
\hline Sorvete & $27,39(5,89)$ & $0,956^{* *}$ & $1,000^{* *}$ & $1,129^{* *}$ & $0,889^{* *}$ & - & $0,166^{* *}$ \\
\hline Vertical & $27,22(5,33)$ & $0,790^{\star *}$ & $0,834^{\star *}$ & $0,963^{* *}$ & $0,724^{\star *}$ & $-0,166^{\star *}$ & - \\
\hline
\end{tabular}

(1)Testes de comparações múltiplas Tukey HSD: * $p<0,05 ;{ }^{* *} p<0,01$.

Tabela 4. Caraterização da umidade relativa (\%) por abrigo e comparações múltiplas entre os abrigos.

\begin{tabular}{lccccccc}
\hline \multirow{2}{*}{ ABRIGO } & \multirow{2}{*}{$\mathbf{M}(\mathrm{DP})$} & \multicolumn{5}{c}{$\begin{array}{c}\text { COMPARAÇÕES MÚLTIPLAS } \\
\text { (diferenças entre as médias dos abrigos) }\end{array}$} \\
\cline { 3 - 8 } & & Casa & Horizontal & Padrão & Prato & Sorvete & Vertical \\
\hline Casa & $82,01(15,84)$ & - & $0,224^{*}$ & $-0,710^{* *}$ & $-0,065$ & $3,101^{* *}$ & $2,839^{* *}$ \\
Horizontal & $81,78(15,48)$ & $-0,224^{*}$ & - & $-0,934^{* *}$ & $-0,289^{* *}$ & $2,876^{* *}$ & $2,615^{* *}$ \\
Padrão & $82,72(12,38)$ & $0,710^{* *}$ & $0,934^{* *}$ & - & $0,645^{* *}$ & $3,811^{* *}$ & $3,549^{* *}$ \\
Prato & $82,07(16,42)$ & 0,065 & $0,289^{* *}$ & $-0,645^{* *}$ & - & $3,165^{* *}$ & $2,904^{* *}$ \\
Sorvete & $78,90(20,03)$ & $-3,101^{* *}$ & $-2,876^{* *}$ & $-3,811^{* *}$ & $-3,165^{* *}$ & - & $-0,262^{* *}$ \\
Vertical & $79,17(19,40)$ & $-2,839^{* *}$ & $-2,615^{* *}$ & $-3,549^{* *}$ & $-2,904^{* *}$ & $0,262^{* *}$ & - \\
\hline
\end{tabular}

(1)Testes de comparações múltiplas Tukey HSD: ${ }^{*} p<0,05 ;{ }^{* *} p<0,01$.

Figura 19. Temperatura média $\left({ }^{\circ} \mathrm{C}\right)$ por abrigo.

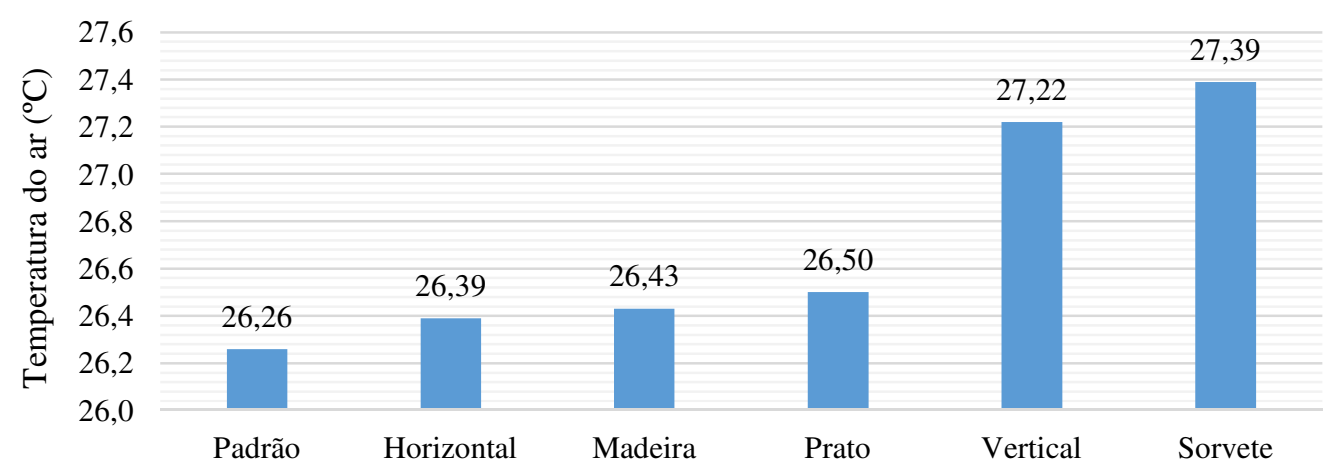

Tipo de abrigo

Quanto à temperatura (Figura 3), apenas não existem diferenças estatisticamente significativas $(p>0,05)$ entre "casa" $(M=26,43 ; \mathrm{DP}=4,12)$ e "horizontal" $(M=26,39 ; \mathrm{DP}=4,08)$. As diferenças são estatisticamente significativas $(p<0,05$ ou $p<0,01)$ nas comparações múltiplas entre todos os outros pares de abrigos.

A análise do gráfico com as temperaturas médias (Figura 19) mostra que o abrigo com temperatura média mais elevada foi o "sorvete" $(M=27,39 ; D P=5,89)$, seguindo-se o "vertical" ( $M=27,22 ; D P$ $=5,33)$, o "prato" ( $M=26,50 ; D P=4,10)$, a "casa" $(M=26,43 ; D P=4,12)$ e "horizontal" $(M=26,39$; $\mathrm{DP}=4,08)$, e o "padrão" ( $\mathrm{M}=26,26 ; \mathrm{DP}=3,43)$ com a temperatura média mais baixa.

Quanto à umidade relativa (Tabela 4), apenas não existem diferenças estatisticamente significativas $(p>0.05)$ entre "casa" $(M=82,01 ; D P=15,84)$ e "prato" $(M=82,07 ; D P=16,42)$. As diferenças foram estatisticamente significativas ( $p<0,05$ ou $p<0,01)$ nas comparações múltiplas entre todos os outros pares de abrigos.

A análise do gráfico com as umidades relativas médias (Figura 20) mostra que o abrigo com umidade relativa média mais elevada foi o "padrão" ( $M=82,07$; $D P=12,38)$, seguindo-se o 
"prato" ( $M=82,07$; $\mathrm{DP}=16,42)$, a "casa" $(\mathrm{M}=82,01$; $\mathrm{DP}=15,84)$ e "horizontal" ( $\mathrm{M}=81,78$; $\mathrm{DP}$ = 15,48), o "vertical" ( $M=79,17 ; \mathrm{DP}=19,40)$, e o "sorvete" $(\mathrm{M}=78,90 ; \mathrm{DP}=20,03) \mathrm{com}$ a umidade relativa média mais baixa.

Figura 20. Umidade relativa média (\%) por abrigo.

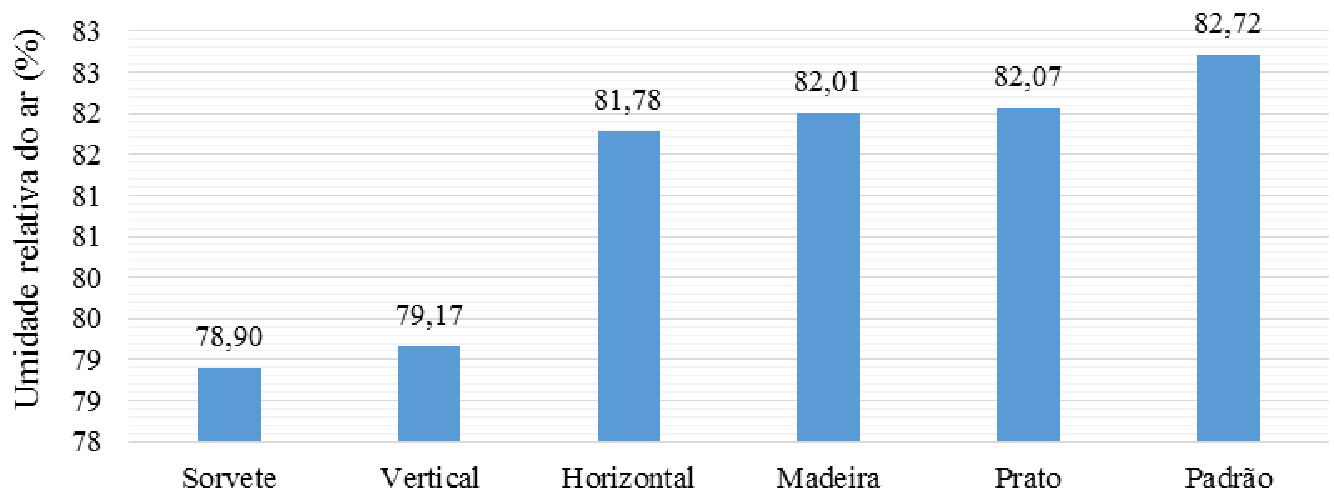

Tipo de abrigo

\section{CUSTO, CONSTRUÇÃO E OPERAÇÃO}

A Tabela 5 traz a composição de custo dos materiais necessários para construção dos abrigos, sendo 0 de menor valor 0 do tipo "Sorvete" por $R \$ 1,50$ (um real e cinquenta centavos), seguido pelo "Horizontal" por $\mathrm{R} \$ 19,96$ (dezenove reais e noventa e seis centavos), após o "Vertical" por $\mathrm{R} \$ 29,39$ (vinte e nove reais e trinta e nove centavos), o "Prato" por $\mathrm{R} \$ 33,20$ (trinta e três reais e vinte centavos) e o de maior custo foi o de "Madeira" por $\mathrm{R} \$ 101,40$ (cento e um reais e quarenta centavos).

Tabela 5. Custo dos matérias para fabricação dos abrigos alternativos

\begin{tabular}{|c|c|c|c|c|c|}
\hline Item & Descrição & $\begin{array}{c}\text { Unidade de } \\
\text { comercialização }\end{array}$ & $\begin{array}{c}\text { Valor } \\
\text { Unitário } \\
\text { (R\$) }\end{array}$ & $\begin{array}{l}\text { Quantidade } \\
\text { necessária }\end{array}$ & $\begin{array}{l}\text { Valor } \\
\text { Total } \\
\text { (R\$) }\end{array}$ \\
\hline 1. & HORIZONTAL & & & & \\
\hline 1.1 & Tubo esgoto $100 \mathrm{~mm}$ & Barra $6 \mathrm{~m}$ & 35,49 & 0,60 & 3,55 \\
\hline 1.2 & Tubo esgoto $75 \mathrm{~mm}$ & Barra $6 \mathrm{~m}$ & 37,28 & 0,50 & 3,11 \\
\hline 1.3 & Papel aluminizado & Rolo & 7,00 & 1,00 & 7,00 \\
\hline 1.4 & Cola & Tubo & 1,50 & 1,00 & 1,50 \\
\hline 1.5 & Parafuso & Unid. & 0,80 & $\begin{array}{r}6,00 \\
\text { TOTAL }=\end{array}$ & $\begin{array}{r}4,80 \\
19,96\end{array}$ \\
\hline 2. & VERTICAL & & & & \\
\hline 2.1 & Tubo esgoto $75 \mathrm{~mm}$ & Barra 6 m & 37,28 & 0,25 & 1,55 \\
\hline 2.2 & CAP esgoto $75 \mathrm{~mm}$ & Unid. & 3,90 & 1 & 3,90 \\
\hline 2.3 & Nípel roscavel 1/2 & Unid. & 0,53 & 2 & 1,06 \\
\hline 2.4 & Joelho roscavel $1 / 2$ & Unid. & 0,88 & 1 & 0,88 \\
\hline 2.5 & Cano de água $1 / 2$ & Barra $6 \mathrm{~m}$ & 20,00 & 1 & 20,00 \\
\hline \multirow[t]{2}{*}{2.6} & Esponja (limpeza / cozinha) & Unid. & 2,00 & 1 & 2,00 \\
\hline & & & & TOTAL = & 29,39 \\
\hline 3. & PRATO & & & & \\
\hline 3.1 & Prato plástico branco & Unid. & 3,00 & 6,00 & 18,00 \\
\hline 3.2 & Mangueira de nível 1/4' & Metro & 1,00 & 0,25 & 0,25 \\
\hline 3.3 & Barra roscada $3 / 8$ - 1 metro & Unid. & 8,71 & 1,00 & 8,71 \\
\hline 3.4 & Porca & Unid. & 0,20 & 12,00 & 2,40 \\
\hline 3.5 & Porca borboleta & Unid. & 0,80 & 2,00 & 1,60 \\
\hline \multirow[t]{2}{*}{3.6} & Arruela & Unid. & 0,16 & 14,00 & 2,24 \\
\hline & & & & TOTAL = & 33,20 \\
\hline 4. & SORVETE & & & & \\
\hline 4.1 & Pote 2l branco com tampa & Unid. & 1,50 & 1 & 1,50 \\
\hline & & & & TOTAL = & 1,50 \\
\hline
\end{tabular}

\begin{tabular}{|c|}
\hline Caminhos de Geografia \\
\hline
\end{tabular}


Painel $2440 \mathrm{~mm} \times 1220 \mathrm{~mm} \times 2,5 \mathrm{~mm}$

Tinta branca esmalte

Dobradiça para Porta 3.1/2" Aço

Parafuso $\mathrm{m}^{2}$

Lata 3,6I

Unid.

Unid.
14,00

35,60

7,90

0,80

\begin{tabular}{rr}
1,3 & 18,20 \\
1 & 35,60 \\
4 & 31,60 \\
20 & 16,00 \\
TOTAL $=$ & $\mathbf{1 0 1 , 4 0}$ \\
\hline
\end{tabular}

Para a construção dos abrigos, é importante ressaltar que os tipos Horizontal, Vertical, Prato e Sorvete puderam ser confeccionados de maneira simples e "artesanal", enquanto que o "Madeira" foi necessário equipamento e mão de obra específica para o corte das chapas de madeira.

\section{CONSIDERAÇÕES FINAIS}

Com base no desempenho dos abrigos alternativos analisados, tem-se que os abrigos do tipo vertical e o sorvete não se demonstram eficientes para a coleta de dados em pontos fixos, principalmente se utilizados durante o dia.

É possível também concluir que não apenas o material utilizado está associado ao desempenho, mas também quanto à sua arquitetura, pois como observado nos abrigos "vertical" e "horizontal' que ambos foram construídos com PVC e apresentaram resultados diferentes.

Quanto aos demais tipos (prato, horizontal e o de madeira) se mostraram alternativas viáveis, cabendo analisar o local onde será utilizado para definir qual deles melhor se adapta, pois o horizontal depende de já conhecer o sentido da direção do vento; o de madeira do espaço disponível devido ao seu tamanho e peso; e quanto ao de prato da disponibilidade de pratos plásticos na cor branca.

Para trabalhos futuros recomenda-se verificar o desempenho dos diferentes abrigos em transecto móvel.

\section{REFERÊNCIAS}

ARMANI, G.; GALVANI, E. Avaliação do desempenho de um abrigo meteorológico de baixo custo. Revista Brasileira de Agrometeorologia, v. 14, pp. 34-40, 2006.

BARROS, M. P. Dimensão fractal e ilhas de calor urbanas: uma abordagem sistêmica sobre as implicações entre a fragmentação das áreas verdes e o ambiente térmico do espaço urbano. 2012, Tese (Doutorado em Física Ambiental) Cuiabá, MT: UFMT.

CAMPELO JUNIOR, J. H.; PRIANTE FILHO, N.; CASEIRO, F.T. Caracterização macroclimática de Cuiabá. Encontro Nacional de Estudos sobre o Meio Ambiente. 1991.

CASTELHANO, F.J., ROSEGHINI, W.F.F. A utilização de policloreto de vinila (PVC) na construção de mini-abrigos meteorologicos para aplicação em campo. Revista Brasileira de Climatologia, v. 9, pp. 48-55. 2011.

COSTA, A.; LABAKI, L. C.; ARAÚJO, V. M. D. A methodology to study the urban distribution of air temperature in fixed points. Procedings of 2nd PALENC Conference and 8th AIVC Conference. 2007, pp. 227-230.

COX, E. P. Interação entre clima e superfície urbanizada: o caso da cidade de Várzea Grande/MT. 2008. Dissertação (Mestrado em Física Ambiental) - Cuiabá, MT: UFMT.

DAVIS INSTRUMENTS. Wireless Vantage Pro2 ${ }^{\mathrm{TM}}$ with Standard Radiation Shield. DAVIS. Disponível em: http://www.davisnet.com/weather/products/weather_product.asp?pnum=06152>. Acesso em: 01 de maio de 2015.

FRANCO, F. M. Análise do comportamento termo-higrométrico urbano sob a ótica do uso e ocupação do solo em Cuiabá - MT. 2013. Tese (Doutorado em Física Ambiental) Cuiabá, MT: UFMT.

Configuração Urbana e sua Interferência no Microclima Local: Estudo de Caso no Bairro do Porto em Cuiabá-MT. 2010. Dissertação (Mestrado em Física Ambiental) - Cuiabá, MT: UFMT. 
GIVONI, B. Man, climate and architecture, Applied Science Publishers, London, 2nd. 1976.

MAITELLI, G. T. Uma abordagem Tridimensional do clima urbano em área Tropical Continental: o exemplo de Cuiabá/MT. 1994. Tese (Doutorado em Climatologia): USP.

NINCE, P. C. C.. Vegetação e revestimentos urbanos: : implicações na sensação térmica dos usuários do campus da UFMT em Cuiabá-MT. 2013 Tese (Doutorado em Física Ambiental) Cuiabá, MT: UFMT.

OKE, T. R. Towards better scientific communication in urban climate. Austria : Theorical and Applied Climatology, 2005.

OLIVEIRA, A. S. Análise de desempenho térmico e consumo de energia em residências na cidade de Cuiabá/MT: estudo de caso. 2007. Dissertação (Mestrado em Física Ambiental) - Cuiabá, MT: UFMT.

Onset Computer Corporation. HOBO U12 Temperature/Relative Humidity/Light/External Data Logger - U12-012. Disponível em: <http://www.onsetcomp.com/products/dataloggers/u12-012>. Acesso em: 11 de março de 2015.

RIBEIRO, K. F. A.; VALIN JR, M. O.; SANTOS, F. M. M.; NOGUEIRA, M. C. J. A; NOGUEIRA, J. S.; DE MUSIS, C. R. Análise da temperatura interna e superficial em diferentes sombreamentos arbóreos. Revista da Sociedade Brasileira de Arborização Urbana REVSBAU, Piracicaba - SP, v.10, n.2, p. 40-60, 2015.

SANTOS, F. M. M. Influência da ocupação do solo na variação termo-higrométrica na cidade de Cuiabá-MT. 2012. Tese (Doutorado em Física Ambiental) Cuiabá, MT: UFMT. 